\title{
Clinical features as discriminating factors in the choice of tracheostomy techniques
}

\author{
Lucia Marullo, Giuseppe Izzo, Annarita Orsini, Jole Petruzzi, Anna d'Elia, Luana Vessicchio, Fausto Ferraro \\ From 26th National Congress of the Italian Society of Geriatric Surgery \\ Naples, Italy. 19-22 June 2013
}

\begin{abstract}
Introduction
Tracheostomy is a generally accepted procedure that assures free access to the airways in long-term lung ventilation. Apart from surgical tracheostomy, percutaneous dilational tracheostomy (PDT) has been increasingly employed in intensive care units (ICU). There is no optimal tracheostomy (TS) technique and in comparisons of percutaneous techniques, no single technique has proved to be superior. For this reason, the operator's skill and experience and the clinical anatomical and physiopathological features of the patient should be discriminating factors in the choice of TS technique. Because of this we developed a decisional making algorithm as a guide to choose tracheostomy method more adapted to critical patients' characteristics. It's use in elective TS in ICU seems to reduce complications in our exeprience, regarding leterature data.
\end{abstract}

\section{Background}

TS is an elective technique used in ICU for the management of patients requiring prolonged mechanical ventilation (MV) [1]. When elective tracheotomy is indicated in critically ill patients, the technique of PDT offers important advantages over surgical tracheosthomy (ST). With PDT, less clinically significant wound infection is observed compared with ST, probably due to minimisation of local tissue trauma and a tighter fit between cannula and the surrounding tissues. Nowadays more PDT methods are in use: TLT, Ciaglia blue-Rhino, PercuTwist [1], Ciaglia Blue-Dolphin. But considering the clinical and anatomical variability of ICU patients, there is no ideal risk-free TS technique. Operator's experience and patient's physiopathological characteristics should be always considered [2]. Because of this our dedicated

\footnotetext{
* Correspondence: fausto.ferraro@unina2.it
Dept. of Anesth. Surgical and Emergency Sciences-Intensive Care Unit II

* Correspondence: fausto.ferraro@unina2.it
Dept. of Anesth. Surgical and Emergency Sciences-Intensive Care Unit I University of Naples, Italy
}

\section{Method}

We have considered consecutive 118 patients, admitted in a general intensive care of our University Hospital in the last three years, skeduled for tracheostomy. Generally in our practice TS is performed by residents after a specific training program under the guidance and supervision of a senior tutor with specific skills. Each patient was evaluated by ultra sounds (US), and video-bronchoscopy (video-FBS). Algorithm was formulated by our ten-years-experince with TS techniques, comparing the specific characteristics of each technique to the physiopathological characteristics of each patient. Figure 1.

\section{Results and discussion}

We recorded complications related to tracheostomy performed, applying the decisional making algorithm, in the last 3 years.

Comparing with the complications reported in the literature [3-5] (Table 1), the use of our decisional flowchart as guide to choose the kind of PDT thecnique seems to reduce the incidence of complications considered (Table 1).

The systematic use of U.S. and video-FBS facilitates the execution of the TS and reduces complications [3]. In our observational retrospective study we have a small case series without control group; it is insufficient for a statistical validation of the findings (118 patients in the last three years), even if quantitatively similar with other monocentric study in literature. Furthermore, in our general university ICU polytrauma and cardiac surgical patients are less frequent then septic, surgical or COPD patients. Because of this our 
Table 1 Algorithm complications vs Literature complications.

\begin{tabular}{|c|c|c|c|c|c|c|c|c|c|}
\hline Tracheostomy Technique & CBD & $\mathrm{BC}$ & CBR & P-Twist & TLT & Surgical & Total & Study group & Literature \\
\hline Patients $\mathrm{n}$. & 16 & 2 & 44 & 9 & 15 & 2 & 118 & & \\
\hline Complications & & & & & & & & $\%$ & $\%$ \\
\hline Bleeding & 1 & 0 & 2 & 0 & 0 & 0 & & $2.50 \%$ & $1,2 \%-4,65 \%$ \\
\hline Ring fractures & 3 & 0 & 0 & 8 & 0 & 0 & & $10.20 \%$ & $?$ \\
\hline Stenosys & 0 & 0 & 2 & 0 & 1 & 0 & & $2.50 \%$ & $0,8 \%-3,7 \%$ \\
\hline Edema & 3 & 0 & 3 & 0 & 0 & 0 & & $5.00 \%$ & $3.40 \%$ \\
\hline Tracheoesofagea fistula & 1 & 0 & 0 & 0 & 0 & 0 & & $0.85 \%$ & $?$ \\
\hline Pneumothorax & 0 & 0 & 0 & 0 & 0 & 0 & & $0.00 \%$ & $0.4-3 \%$ \\
\hline Subcutaneous emphysema & 0 & 0 & 0 & 0 & 0 & 0 & & $0.00 \%$ & $1312.00 \%$ \\
\hline
\end{tabular}

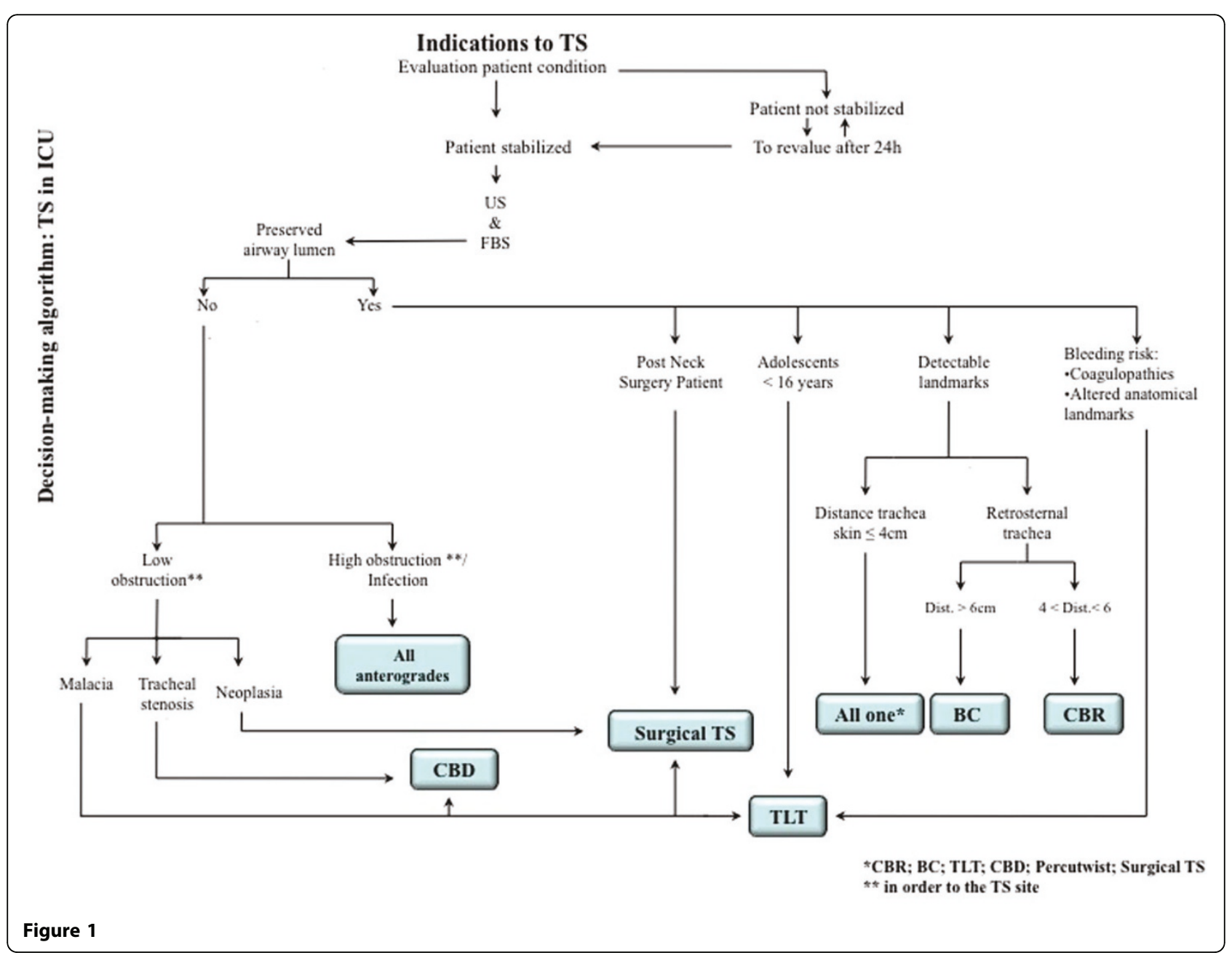

decisional making algorithm should be evaluated on a more heterogeneous population. The application of our algorithm required knowledge, skill and availability of at least three techniques: surgical, intrusive and extrusive percutaneous oncewith costs increased. But the reduction of complications would lead to a reduction in ICU stay and in health care costs [2].

\section{Conclusions}

The application of our algorithm to choose which kind of TS technique was more adapt to the peculiarities of each patient, seems to reduce incidence of complications, compared to the incidence reported in literature. To validate our useful experience we need a randomized controlled multicentric study. 


\section{References}

1. Peris A, et al: Percutaneous dilatational tracheostomy: a self-drive control technique with video fiberoptic bronchoscopy reduces perioperative complications. Minerva Anestesiol 2009, 75:21-5.

2. Pelosi $P$, Severgnini P: Tracheostomy must be individualized! Crit. Care 2004, 8(5):322-4

3. Kollig E, Heydenreich U, Roetman B, et al: Ultrasound and bronchoscopic controlled percutaneous tracheostomy on trauma UCI. Injury 2000, 31:663-8.

4. Marx WH, et al: Some important details in the technique of percutaneous dilational tracheostomy via the modified Seldinger technique. Chest 1996, 110:762-766.

5. François B, et al: Complications of tracheostomy performed in the ICU: subthyroid tracheostomy vs surgical cricothyroidotomy. Chest 2003, 123(1):151-8.

doi:10.1186/1471-2482-13-S1-A28

Cite this article as: Marullo et al: Clinical features as discriminating factors in the choice of tracheostomy techniques. BMC Surgery 201313 (Suppl 1):A28.

\section{Submit your next manuscript to BioMed Central} and take full advantage of:

- Convenient online submission

- Thorough peer review

- No space constraints or color figure charges

- Immediate publication on acceptance

- Inclusion in PubMed, CAS, Scopus and Google Scholar

- Research which is freely available for redistribution

Submit your manuscript at www.biomedcentral.com/submit 